\title{
Immunoexpression of napsin a in renal neoplasms
}

Bing Zhu, Stephen M Rohan and Xiaogi Lin

\begin{abstract}
Background: Immunohistochemistry (IHC) for napsin A has been widely used to support a diagnosis of lung adenocarcinoma with high sensitivity. In this study, we evaluated immunoreactivity for napsin A in a broad spectrum of renal neoplasms by using tissue microarrays (TMA).

Methods: Duplicate TMA of 159 surgically excised renal neoplasms of various types were constructed. $I H C$ for napsin A was performed on TMAs with appropriate positive and negative controls.

Results: Napsin A was expressed in Acquired cystic disease associated renal cell carcinoma (RCC) (2/2, 100.0\%), chromophobe RCC $(5 / 45,11.1 \%)$, clear cell RCC $(10 / 23,43.5 \%)$, clear cell papillary RCC $(9 / 19,47.4 \%)$, metanephric adenoma (3/3, 100.0\%), oncocytoma (13/23, 56.5\%), and papillary RCC (31/37, 83.8\%). Expression of napsin A was not seen in mucinous tubular and spindle cell carcinoma (0/1, 0.0\%), TFE/MITF RCC 0/1, 0.0\%), and urothelial carcinoma $(0 / 6,0.0 \%)$.

Conclusions: Napsin A is expressed in both common and rare sub-types of renal neoplasms with variable sensitivity. Based on our results, napsin A is not specific for lung adenocarcinoma. When a metastatic carcinoma of unknown primary is positive for napsin A, the differential diagnosis should include tumors of both renal and lung origin.

Virtual slides: The virtual slide(s) for this article can be found here: http://www.diagnosticpathology.diagnomx. eu/vs/9558727831304717.
\end{abstract}

Keywords: Renal neoplasm, Napsin A, Immunohistochemistry

\section{Background}

Napsin A is an aspartic proteinase [1], an enzyme of the pepsin family. Napsin A is expressed in type II pneumocytes and alveolar macrophages of the lung, the proximal and convoluted tubules of the kidney, and acini and ducts of the pancreas [1,2]. Immunohistochemistry (IHC) for napsin A has been widely used to support a diagnosis of lung adenocarcinoma with reported high sensitivity (59\% - 100\%) [3-6], specificity (88 - 94\%) [5,6], positive predictive value $(78-90 \%)[5,6]$, and negative predictive value $(72-96 \%)$ [5-7]. The reported sensitivity and specificity of immunohistochemical labeling for napsin A and TTF-1 for supporting the diagnosis of primary lung adenocarcinoma are controversial due to difference in case number (155 vs. 1674 cases), and tumor area (tissue block vs, tissue microarray) [6,7]. It is well established that distinguishing primary lung adenocarcinoma

\footnotetext{
*Correspondence: xlin@northwestern.edu

Department of Pathology, Northwestern Memorial Hospital, Feinberg School of Medicine, Northwestern University, 251 E. Huron St., Galter Pavilion 7-132 F, Chicago, IL 60611, USA
}

(c) 2015 Zhu et al.; licensee BioMed Central. This is an Open Access article distributed under the terms of the Creative Commons Attribution License (http://creativecommons.org/licenses/by/4.0), which permits unrestricted use, distribution, and reproduction in any medium, provided the original work is properly credited. The Creative Commons Public Domain Dedication waiver (http://creativecommons.org/publicdomain/zero/1.0/) applies to the data made available in this article, unless otherwise stated. from squamous cell carcinoma, and neuroendocrine carcinomas (including small cell carcinoma) is clinically important $[3,4,7]$.

In addition to the expression of napsin $\mathrm{A}$ in lung adenocarcinoma, immunoreactivity for napsin A has also been documented in $5.3-48.3 \%$ of papillary thyroid carcinomas [3,4], 79.0 - 87.5\% of papillary renal cell carcinomas (RCC) [3,4,7], $29.4-52 \%$ of clear cell RCC [3,4,7], $3.9-20.0 \%$ of chromophobe RCC [3,4], $5-20 \%$ of hepatocellular carcinoma [6,7], and $8-20 \%$ of endometrial adenocarcinoma [3,7]. Other tumor types, such as squamous cell carcinoma $(0-3 \%$ [7]), oncocytoma [3], colonic adenocarcinoma $(0-2 \%$ [7]), pancreatic adenocarcinoma (0 - 4\% [7]), gastric adenocarcinoma, mesothelioma, ovarian carcinoma $(0-6 \%$ [7]), urothelial carcinoma, prostate adenocarcinoma, and breast adenocarcinoma ( 0 - 3\% [7]), have been described as being negative or very rarely positive for napsin A [3,4,6,7].

The new international society of urological pathology (ISUP) Vancouver classification of renal neoplasia classifies renal neoplasms into broad categories including 
renal cell tumors, metanephric tumors, nephroblastic tumors, mesenchymal tumors, mixed mesenchymal and epithelial tumors, neuroendocrine tumors, hematopoietic and lymphoid tumors, germ cell tumors, metastatic tumors and other tumors [8]. As Napsin A has been shown to be expressed in some types of epithelial neoplasms, in this study, we evaluated the immunoreactivity for napsin A in a broad spectrum of epithelial renal neoplasms classified according to the new ISUP classification-including novel, recently described sub-types.

\section{Methods}

\section{Patients}

This study was approved by our Institution Review Board. One hundred and fifty nine renal neoplasms that had undergone resection at our institution between January 1 , 2003 and December 31, 2012 were selected based on the availability of $H \& E$ slides and sufficient tissue in the corresponding paraffin blocks to perform the studies outlined herein. All H\&E slides from each case were reviewed by a fellowship trained genitourinary pathologist (SMR). The tumors were classified based on the international society of urological pathology (ISUP) Vancouver classification of renal neoplasm [8]. These tumors included 45 chromophobe RCC, 37 papillary RCC, 23 clear cell RCC, 23 oncocytoma, 19 clear cell papillary RCC, 2 acquired cystic disease associated RCC, 3 metanephric adenoma, 1 mucinous tubular and spindle cell carcinoma, 1 RCC associated with an Xp11.2 translocations/TFE3 gene fusion (TFE/MITF RCC), and 6 urothelial carcinomas of the renal pelvis (Table 1).

\section{Construction of tissue microarrays}

After review of all H\&E stained slides from a given case, a single tumor containing paraffin block was chosen for inclusion in a tissue microarray (TMA). For this study, duplicate TMAs were constructed using $2 \mathrm{~mm}$ tissue cores.

Table 1 Expression of Napsin A in renal neoplasms

\begin{tabular}{lll}
\hline Neoplasms & No. & Napsin A No. (\%) \\
\hline Acquired cystic disease associated RCC & 2 & $2(100.0)$ \\
Chromophobe RCC & 45 & $5(11.1)$ \\
Clear cell RCC & 23 & $10(43.5)$ \\
Clear cell papillary RCC & 19 & $9(47.4)$ \\
Metanephric adenoma & 3 & $3(100.0)$ \\
Mucinous tubular and spindle cell carcinoma & 1 & $0(0.0)$ \\
Oncocytoma & 23 & $13(56.5)$ \\
Papillary RCC & 37 & $31(83.8)$ \\
TFE/MITF RCC* & 1 & $0(0.0)$ \\
Urothelial carcinoma & 6 & $0(0.0)$ \\
\hline
\end{tabular}

*: TFE/MITF RCC: RCC associated with Xp11.2 translocations/TFE3 gene fusions.

\section{Immunohistochemistry}

An immunohistochemical (IHC) stain for Napsin A (Catalog CM388CK, Biocare Medical, Concord, CA) was performed on sections from the TMAs on an automated stainer with appropriate positive (lung adenocarcinoma) and negative controls (colon and prostate adenocarcinomas) [9]. Paraffin-embedded blocks were sectioned, deparaffinized, rehydrated, and blocked with methanolic $3 \%$ hydrogen peroxide. Antigen retrieval was performed in citrate buffer. After incubation with the primary antiNapsin A antibody, the detection was performed with Iview DAB detection kit (Catalog number 760-091, Ventana, Tucson, AZ). The cut off for positive staining is at least $5 \%$ of cells with moderate or strong intensity staining for napsin A. Only cytoplasmic dot staining was recognized as positive stain. When evaluating the TMA, the immunopositivity for macrophages and "edge effect", with positivity seen at the edges of the TMA and negativity at the center of the TMA, should be excluded [9].

\section{Results}

\section{Expression of napsin a in renal neoplasms}

Expression of napsin A was detected in most of renal neoplasms with variable frequency (Table 1 and Figure 1). High frequency of napsin A expression was found in acquired cystic disease associated RCC (100.0\%), metanephric adenoma (100.0\%), oncocytoma (56.5\%) and papillary RCC (83.8\%). For metanephric adenoma, the granular cytoplasmic labeling was subtle relative to other tumor types due to scant nature of the cytoplasm in metanephric adenomas. Low frequency of napsin A expression was found in chromophobe RCC (11.1\%), clear cell RCC (43.5\%), and clear cell papillary RCC (47.4\%). Expression of napsin A was not detected in mucinous tubular and spindle cell carcinoma, TFE/MITF RCC, or urothelial carcinoma of the renal pelvis.

\section{Discussion}

In this study, we found that napsin $\mathrm{A}$ is expressed in various types of renal neoplasms with variable sensitivities. Our results may have implications in various clinical settings, including the evaluation of needle core biopsies of renal masses and the work up of metastatic carcinomas from unknown primary sites.

We found that immunoreactivity for napsin A was seen in all acquired cystic disease associated RCC and metanephric adenomas (100\%). Approximately one-half (47.4\%) of the recently described entity clear cell papillary RCC also labeled for Napsin A. Immunoreactivity for napsin A was not seen in mucinous tubular and spindle cell carcinoma or TFE/MITF RCC. To the best of our knowledge, no study has previously reported on the immunoreactivity of Napsin A in these specific renal 


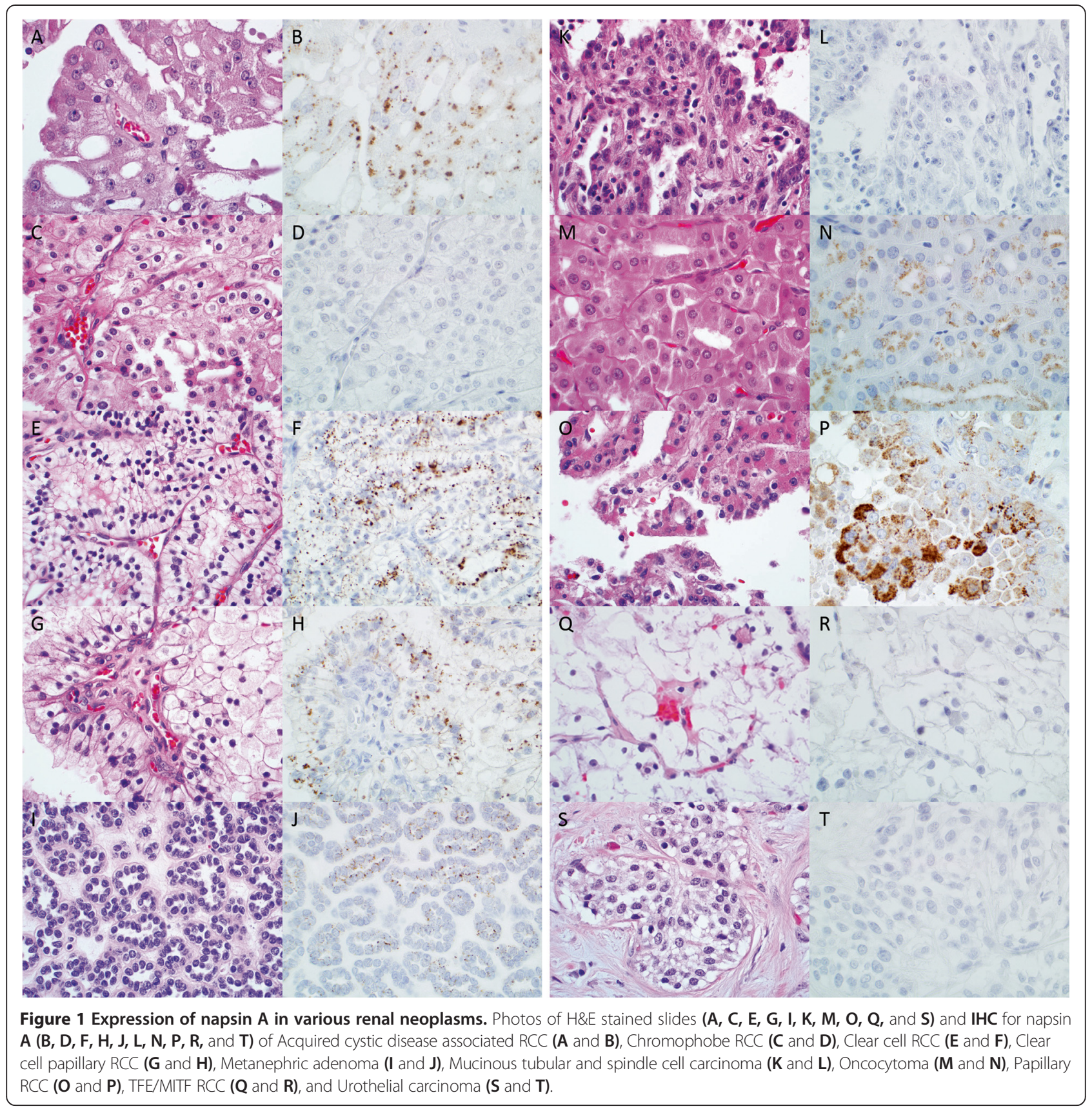

tumor types. Therefore, IHC for napsin A may help to distinguish these renal neoplasms, especially on renal biopsy specimens.

In this study, we evaluated the immunoreactivity of napsin A in a larger number of oncocytomas and chromophobe RCC and found that immunoreactivity for napsin A was seen in 56.5\% oncocytoma, which is different from a previous report (0\%) [3]. This is probably due to the inclusion of larger number of cases in our study ( 23 vs. 3 cases), and the different antibodies used in the studies (Biocare Medical vs. Novocastra) that may result in difference in staining pattern due to different affinity to the antigen. Immunoreactivity for napsin A was detected in $11.1 \%$ chromophobe RCC in our study, which falls within the range of previously reported napsin A immunoreactivity $(2.9-20 \%)$ in this tumor type [3,4]. The huch higher rate of $20 \%$ immunoreactivity for napsin A in chromophobe RCC previously reported may be due to the limited number of cases used in the prior study (5 cases vs. 45 cases in our study) [3]. The finding of relative overexpression of napsin A in oncocytomas versus chromophobe RCC (56.5\% versus $11 \%$ ) may be helpful in distinguishing these two tumor types from one another. 
In this study, we found that immunoreactivity for napsin A was present in several renal neoplasms with similar frequencies as those reported previously. Immunoreactivity for napsin A was detected in $43.5 \%$ clear cell RCC, which is in the range of previously reported sensitivity (29.4 $52 \%)[3,4,7]$. We also found that immunoreactivity for napsin A was seen in $83.8 \%$ papillary RCC, which is similar to prior published studies $(79.0-87.5 \%)$ [3,4,7]. We did not observe immunoreactivity for napsin A in urothelial carcinomas of the renal pelvis, a finding which has been noted by others [7].

Traditionally, all localized solid renal masses have been considered potentially malignant and treated with surgical excision, most often radical nephrectomy, in an effort to minimize the risk of metastatic dissemination [10]. However, renal biopsy has a definite and expanding role in the evaluation and treatment of renal masses. Clinically, one of the most obvious uses of biopsy of kidney masses is to distinguish a primary renal neoplasm from a metastatic malignancy. Based on our results, if the biopsied tumor is positive for napsin A, the differential diagnosis is broad and should include both primary renal tumors and metastatic tumors. Immunoreactivity for napsin A can be seen in lung adenocarcinoma [3-7], papillary thyroid carcinoma $[3,4]$, hepatocellular carcinoma [6,7], and endometrial adenocarcinoma $[3,7]$ as well as the renal tumor subtypes identified in this study. In general, if immunohistochemistry is required when evaluating a needle core biopsy or cellblocks of a renal mass a broad panel should be employed. A recent article highlighted the utility of a panel that includes CA IX, CD10, AMACR, CK7, and CD117 if the differential diagnosis is limited to common primary renal tumors-such as clear cell RCC, papillary RCC, and chromophobe RCC [11]. If the differential diagnosis of a tumor sampled by needle core biopsy includes a metastatic carcinoma-such as a lung metastasis, then additional markers such as PAX8, TTF-1, and napsin A can be employed with the caveat that none of these markers are $100 \%$ specific or sensitive for a given diagnosis. When dealing with a napsin A positive metastatic carcinoma of unknown primary involving the lung, bone, liver, or other sites the immunoprofile must be considered in the context of the clinical and radiographic history. Essentially, the reader should be wary of basing a diagnosis of site of origin solely on napsin A labeling. Additionally it is important to be aware of the fact that RCC frequently metastasizes to the lung and that the majority of pulmonary metastases of RCC are of the clear cell type. In our study, we found that $47.5 \%$ of clear cell RCCs were positive for Napsina A. When dealing with a tumor in the lung if the differential diagnosis includes lung adenocarcinoma versus renal cell carcinoma including clear cell RCC, IHC for TTF-1, PAX-8, and vimentin in addition to napsin A may be helpful. Finally, based on prior reports nonpulmonary napsin A-positive tumors generally stain weakly positive when compared to lung adenocarcinoma. In addition, the presence of macrophages and background staining should be considered when interpreting results [7]. One should also be aware of the existence of TTF-1 negative, napsin A-positive pulmonary adenocarcinoma.

We included a few uncommon renal tumors in the study. Napsin A was immunoreactive in 2 of $2(100 \%)$ acquired cystic disease associated RCC, 3 of 3 (100\%) metanephric adenoma, 0 of $1(0 \%)$ mucinous tubular and spindle cell carcinoma, and 0/1 (0\%) TFE/MITF RCC. The definitive conclusion for Napsina A expression in these rare tumors with small case number needs further studies by inter-institutional collaboration in future.

\section{Conclusions}

In summary, our results show that napsin A is expressed in a broad spectrum of renal neoplasms with varying frequency. When a metastatic carcinoma of unknown primary is positive for napsin A, the differential diagnosis should include tumors of both renal and lung origin. if both renal cell carcinoma and lung adenocarcinoma are in the differential diagnosis based on morphology and/or clinical history a broad IHC panel including TTF-1, PAX8 and vimentin should be applied for a definitive diagnosis. Napsin A may be a helpful marker in the differential diagnosis of oncocytoma and chromophobe RCC and further studies on this topic with a larger number of cases is warranted.

\section{Competing interests}

All authors declare that they have no competing interests.

\section{Authors' contributions}

BZ and SR carried out selection of the cases, preparation of the tissue microarrays and evaluation of the histology and immunohistochemical results, and drafted the manuscript. $\mathrm{XL}$ designed the studies, carried out preparation of the tissue microarrays, evaluation of the histology and immunohistochemical results and statistic analysis, and drafted the manuscript. All authors read and approved the final manuscript.

\section{Acknowledgements}

This study was supported by the start-up fund of Dr. Xiaoqi Lin. All authors fully disclosed no financial conflicts of interest in the Support/Grant Information text box, as well as no ethical conflicts of interest.

Received: 27 May 2014 Accepted: 4 March 2015

Published online: 14 March 2015

\section{References}

1. Mori K, Shimizu H, Konno A, Iwanaga T. Immunohistochemical localization of napsin and its potential role in protein catabolism in renal proximal tubules. Arch Histol Cytol. 2002;65:359-68.

2. Mori K, Kon Y, Konno A, Iwanaga T. Cellular distribution of napsin (kidney-derived aspartic protease-like protein, KAP) mRNA in the kidney, lung and lymphatic organs of adult and developing mice. Arch Histol Cytol. 2001;64:319-27.

3. Kadivar M, Boozari B. Applications and limitations of immunohistochemical expression of "Napsin-A" in distinguishing lung adenocarcinoma from 
adenocarcinomas of other organs. Appl Immunohistochem Mol Morphol. 2013;21:191-5

4. Bishop JA, Sharma R, Illei PB. Napsin A and thyroid transcription factor-1 expression in carcinomas of the lung, breast, pancreas, colon, kidney, thyroid, and malignant mesothelioma. Hum Pathol. 2010;41:20-5.

5. Terry J, Leung S, Laskin J, Leslie KO, Gown AM, lonescu DN. Optimal immunohistochemical markers for distinguishing lung adenocarcinomas from squamous cell carcinomas in small tumor samples. Am J Surg Pathol. 2010;34:1805-11.

6. Mukhopadhyay S, Katzenstein AL. Comparison of monoclonal napsin A, polyclonal napsin A, and TTF-1 for determining lung origin in metastatic adenocarcinomas. Am J Clin Pathol. 2012;138:703-11.

7. Turner BM, Cagle PT, Sainz IM, Fukuoka J, Shen SS, Jagirdar J. Napsin A, a new marker for lung adenocarcinoma, is complementary and more sensitive and specific than thyroid transcription factor 1 in the differential diagnosis of primary pulmonary carcinoma: evaluation of 1674 cases by tissue microarray. Arch Pathol Lab Med. 2012;136:163-71.

8. Srigley JR, Delahunt B, Eble JN, Egevad L, Epstein JI, Grignon D, et al. The International Society of Urological Pathology (ISUP) Vancouver Classification of Renal Neoplasia. Am J Surg Pathol. 2013;37:1469-89.

9. Zhu B, Dalal S, Kamp DW, Lin X. Warranting investigation of primary lung adenocarcinoma in patients with an extrapulmonary malignancy and lung nodules due to high frequency. Am J Clin Pathol. 2014;141:429-36.

10. Samplaski MK, Zhou M, Lane BR, Herts B, Campbell SC. Renal mass sampling: an enlightened perspective. Int J Urol. 2011;18:5-19.

11. Al-Ahmadie HA, Alden D, Fine SW, Gopalan A, Touijer KA, Russo P, et al. Role of immunohistochemistry in the evaluation of needle core biopsies in adult renal cortical tumors: an ex vivo study. Am J Surg Pathol. 2011;35:949-61.

\section{Submit your next manuscript to BioMed Central and take full advantage of:}

- Convenient online submission

- Thorough peer review

- No space constraints or color figure charges

- Immediate publication on acceptance

- Inclusion in PubMed, CAS, Scopus and Google Scholar

- Research which is freely available for redistribution 